\title{
An E-learning Space for the Economics Experimental Teaching Based on Pedagogy-Space-Technology Framework
}

\author{
Xing Pan*, Li Zhu \\ Guangdong University of Foreign Studies, Network and Information Center, Guangzhou, China \\ "Corresponding author. Email: pxsine@163.com
}

\begin{abstract}
In order to promote the construction and application of personalized E- learning spaces, this article is based on the Pedagogy-Space-Technology (PST) learning space theory as the research framework, starting from the three core elements of teaching method, space and technology. Study the construction of E-learning space in the experimental teaching scenario of economics and management.
\end{abstract}

Keywords: E-learning spaces, pedagogy-space-technology framework, PST framework, Economics

experimental teaching

\section{INTRODUCTION}

Learning spaces is where learning behavior occurs, it includes physical learning space and E-learning space [1]. In recent years, The Chinese government has made a lot of efforts in building and regulating the use of E-learning spaces. The Ministry of Education has developed many documents to encourage and regulate the use of E-learning spaces $[2,3]$.

However, most of the current online learning spaces are designed to provide a ubiquitous learning environment to solve the function implementation and evaluation problems from a technical level. A large number of studies lack the guidance of advanced learning space theory, do not personalize the design for specific teaching scenarios and tasks, and there are problems such as lack of subjectivity, science, and education [4]. In order to construct and apply the network learning space reasonably, it is necessary to choose a scientific theoretical framework as a guide, combine specific teaching scenarios, and carry out personalized design and implementation according to teaching content and teaching characteristics.

\section{THE PST FRAMEWORK}

The Pedagogy-Space-Technology (PST) Framework (Radcliffe, 2009) is a framework that has been used to guide the creation of new and modern teaching spaces. It is the product of a Carrick Institute-funded Next Generation Learning Spaces (NGLS) project, which was conducted in University of Queensland by Professor Radcliffe. It was developed collaboratively and based on existing key research in this area of teaching and learning (e.g., Olinger, 2005). The NGLS project develops the PST framework by examining the relationship between pedagogy, space and technology. It aims to enable institutions to create new teaching and learning spaces with the objectives of promoting student engagement and learning outcomes. It is an inquiry driven process that is based on Pedagogy, Space and Technology (see Figure 1) and thus, can be suited to the specific needs of the institution.

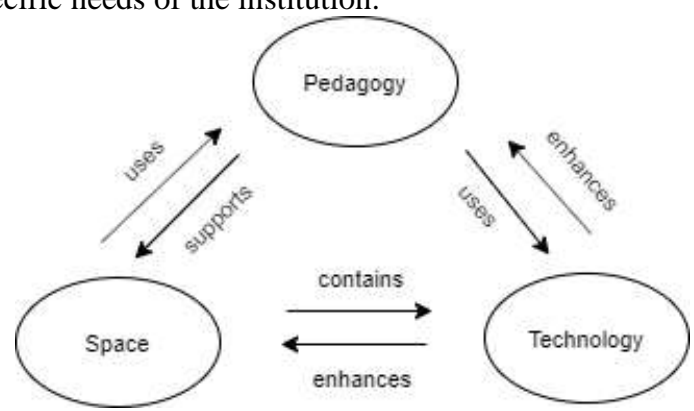

Figure 1 The PST Framework

As figure 1 represents the framework diagrammatically. This framework is designed for a range of users across a wide span of projects and institutions. Within the framework, the three areas of pedagogy space and technology influence each other and key questions for evaluating learning spaces are framed within each of these three areas. The PST framework is useful for all institutions wishing to evaluate the impact of their spaces in these three areas [4].

The PST framework is a question-driven inquiry process synthesized from published literature and knowledge of innovative teaching and learning spaces globally, and informed by lessons learned in developing new learning facilities at The University of Queensland (UQ) over the past decade. It empowers a diverse range of potential stakeholders to consider critically and holistically the pedagogical, technological, and physical aspects of teaching and learning spaces and their interactions. It can be used at 
each stage of the life cycle of a new facility, from conception through stages of design, construction, and operation [5].

Table 1 The PST Framework Life-Cycle [4]

\begin{tabular}{|l|l|l|}
\hline \multirow{2}{*}{ Focus } & \multicolumn{2}{|c|}{ Life-cycle stage } \\
\hline Overall & What is the motivation for the initiative? & What does success look like? \\
\hline Pedagogy & $\begin{array}{l}\text { What types of learning and teaching are we } \\
\text { Operation }\end{array}$ \\
\hline trying to foster? Why? & $\begin{array}{l}\text { What types of learning and } \\
\text { teaching are observed to take } \\
\text { place? What is the evidence? }\end{array}$ \\
& $\begin{array}{l}\text { What aspects of the design of the space and } \\
\text { provisioning of furniture and fitting will } \\
\text { foster these modes of learning (and } \\
\text { teaching)? How? }\end{array}$ & $\begin{array}{l}\text { Which aspects of the space } \\
\text { design and equipment worked } \\
\text { and which did not? Why? }\end{array}$ \\
\hline Technology & $\begin{array}{l}\text { How will technology be deployed to } \\
\text { complement the space design in fostering } \\
\text { the desired learning and teaching patterns? }\end{array}$ & $\begin{array}{l}\text { What technologies were most } \\
\text { effective at enhancing learning } \\
\text { and teaching? Why? }\end{array}$ \\
\hline
\end{tabular}

The table illustrates the basic questions for the various stages of a new facility. Each of these basic questions is expanded into a more detailed set of questions and issues to be considered and guide the process. As an evaluation tool, it links design intent with outcomes, and challenges all concerned to question the what, why and how of initiatives to create new learning spaces. Its generic simplicity means it can be used for any type of learning spaces from a laboratory to a learning common, to more conventional performance space. The framework can also be applied to small- or large-scale projects. It is inherently selfdocumenting and aides the elicitation of lessons learned for future projects. Within UQ, the framework was used to refine various learning spaces such as the new Collaborative Teaching and Learning Centre (CTLC), the Advanced Concept Teaching Space (ACTS), and a next generation library in the Biological Sciences Library.

\section{RESEARCH AND APPLICATION OF PST FRAMEWORK}

A pilot study (Gail Wilson 2012) [5] on implementation and evaluation of a new learning space was started. They investigated the use of a next generation learning space (the Pod Room) by academic staff and students, makes recommendations for further research into the effectiveness of new learning spaces in universities.

An Innovation@CDU Grant Project (Jenny Ng ,2015) [6] which uses the PST Framework to build an online moot court which is able to ensure that both internal students on campus and external students online are able to moot effectively. The project uses Blackboard Collaborate ${ }^{\mathrm{TM}}$ and the PST Framework. The technology has been implemented in Charles Darwin University (CDU) to create the new teaching spaces in CDU. The same technology in the new teaching spaces is then used to build an online moot court.

\section{ANALYSIS OF THE CHARACTERISTICS OF ECONOMICS EXPERIMENT TEACHING}

The Experimental Teaching Center of Guangdong University of Foreign Studies was established in 2013, Including Economic Experimental Teaching Department and Journalistic Art Experimental Teaching Department, The Economic Experimental Teaching Department undertook the task of experimental teaching of economics and management, the main courses are "Business Behavior Simulation" and "Enterprise Resource Planning", The course uses simulation teaching software and hardware, including: manual enterprise sandboxes, supply chain sandboxes, ERP software, and Yue-Chuang Cloud Platform to conduct business simulation operations, and conduct a full range of simulations from business management, decision-making, and data aspects. Compared with other professional courses, the teaching process of this course has the following distinctive features:

(1) Rich curriculum teaching resources. Economic experiment teaching uses a variety of teaching aids, including physical sandboxes, electronic sandboxes, and virtual simulation software. Teaching knowledge points, operating rules, and operating specifications can be 
imparted through the production of graphic courseware, audio, or short videos. The richness of teaching resources.

(2) Strong practical operation. During the teaching process, students need to team up for hands-on exercises. Teachers often lead students to perform manual simulation operations, have an intuitive understanding of business operations and plans, and then use virtual simulation software for online operations. Both links require students to perform a lot of practical operations, and at the same time observe and compare the operation data, and finally form an overall understanding of the business operation.

(3) There are many interactive actions. In teaching activities, there is a close interaction between teachers and students, and between students. At the beginning of the course, teachers should lead students to understand and master market rules, be familiar with the operation of sandbox experiment tools, and group students by lectures. Within the group, students fully communicate, think, judge and judge opponents, and spark the wisdom of each other to form the business strategy of each group. During the business process, each group announces financial statements to the market at the end of each year and places advertisements for the next year the menu is used to form a judgment of the market through information dissemination, and at the same time to mine useful information in the market to conduct possible inter-group transactions. During and after business, the teacher keeps commenting, and each group must share and summarize.

The economics experimental teaching course is rich in teaching resources, strong in teaching practice, and frequent interactive communication, which puts forward high requirements and challenges for the construction of online learning spaces. In order to support multiple types of teaching activities and build an efficient online learning space, the needs of diversity, adaptability, and multimodality should be considered, and all aspects of teaching should be considered. It should be intensive and shared, and can better support autonomous learning, Collaborative learning, and inquiry learning.

\section{CONSTRUCTION OF E-LEARNING SPACE}

Figure 2 is the overall architecture design of the online learning space, which is mainly divided into four layers.
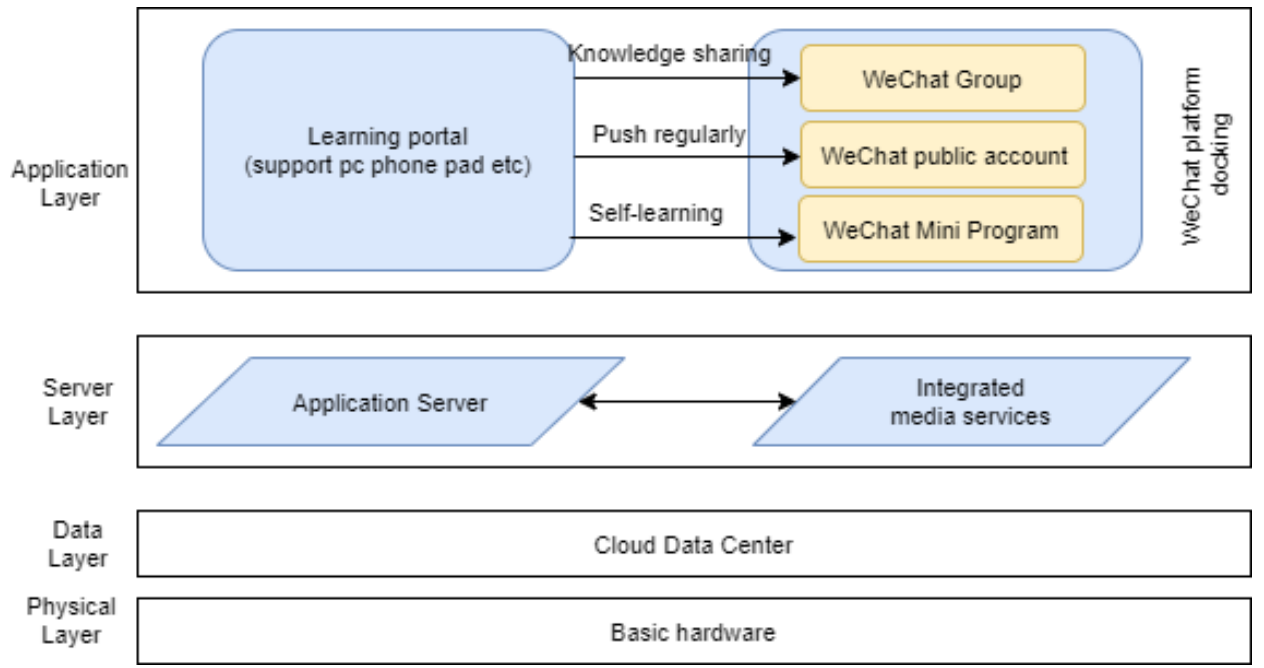

Figure 2 Overall architecture of e-learning platform

(1) Physical layer. Refers to the basic hardware equipment required for system operation, mainly including servers, NSA storage etc.

(2) Data layer. Cloud data center architecture using VMware virtualization technology combined with NSA storage devices.

(3) Server layer. includes integrated media services and application services. The integrated media service is a database processing of sound, video, pictures, text and other data to establish a "media asset database". Using the integrated media architecture will make teaching multimedia easy to reuse in the future. Application services refer to various operations on the resource library constructed by Rong Media Services, including: adding, deleting, modifying, querying, etc., and logging all operations. The service layer specifically refers to the Guangdong University of Foreign Studies University website group platform, which provides both the system operating environment and the background and development environment required for the learning portal. (4) Application layer. Refers to the online learning space that can be directly perceived by teachers and students during the teaching process. The application layer consists of two parts:1)A learning portal based on the development of the Guangdong University of Foreign Studies University website group platform. The portal adopts responsive development and has multi-terminal adaptability. It can classify and index curriculum knowledge, display learning resources provided by the service layer, and generate QR codes or Share the link to publish the knowledge module to 
the formed WeChat learning group ;(2)A mobile learning environment based on Tencent's WeChat products[7], including: learning groups, public accounts, and applets. The learning portal will interface with the WeChat public account and support the regular push of learning resources from the website background to the WeChat public account. If the learning portal and WeChat public account are mainly for displaying and retrieving course knowledge, then the WeChat Mini Program has rich functionality and is ready to run out. It can provide learners with a more interactive learning channel and a learning space. Provides good supplements.

In the above architecture, the main functional modules of the online learning space are at the top of the entire model, located at the service layer and the application layer, and are the parts that teachers and students can directly sense. Figure 5 below shows the main functional modules of the network learning space and their interaction behavior.

\section{FUNCTIONAL MODULE OF E- LEARNING SPACE}

The E-learning space will mainly include five functional modules (Figure 3).

(1) Teacher Management. It can complete the construction, release and maintenance of course knowledge, can upload course-related content (text, PDF, pictures, audio, video, etc.) to the management end, and publish and push to the learning portal and WeChat public account, except for content management and In addition to pushing, the management background will also have functions such as $\log$ auditing and security detection;

(2) Learning portal. The design and development of the front-end page is required. It will be implemented by responsive development and design to achieve multiterminal compatible display for users [8].

(3) WeChat platform. It is composed of a series of related products provided by Tencent: WeChat group, WeChat public account and WeChat mini program. The WeChat Mini Program needs independent development and docking. They are integrated in the chat software WeChat provided by Tencent. The three are related to each other and each performs its role. The WeChat group enables interaction, sharing and answering questions between teachers and students, and students. Push and query; WeChat miniprograms implement functions such as learning breakthroughs, after-school quizzes, punch-in, and homework submission, and provide an online-based course assessment mechanism and conduct course satisfaction surveys. The content in the learning portal can be shared to the WeChat group by linking or generating a QR code to realize the transfer of knowledge between different terminals.

\section{CONCLUSION AND FURTHER RESEARCH}

In this article, we researched and analyzed the PST theoretical framework, and designed an E-learning model based on this framework. In the learning space model, we tried to use different techniques to help improve the teaching effect in the teaching process.

After the development of the E-learning space is completed, it will be implemented and evaluated, it can be applied to teaching activities as a whole in conjunction with the PST framework theory, and group teaching experiments will be carried out subsequently.

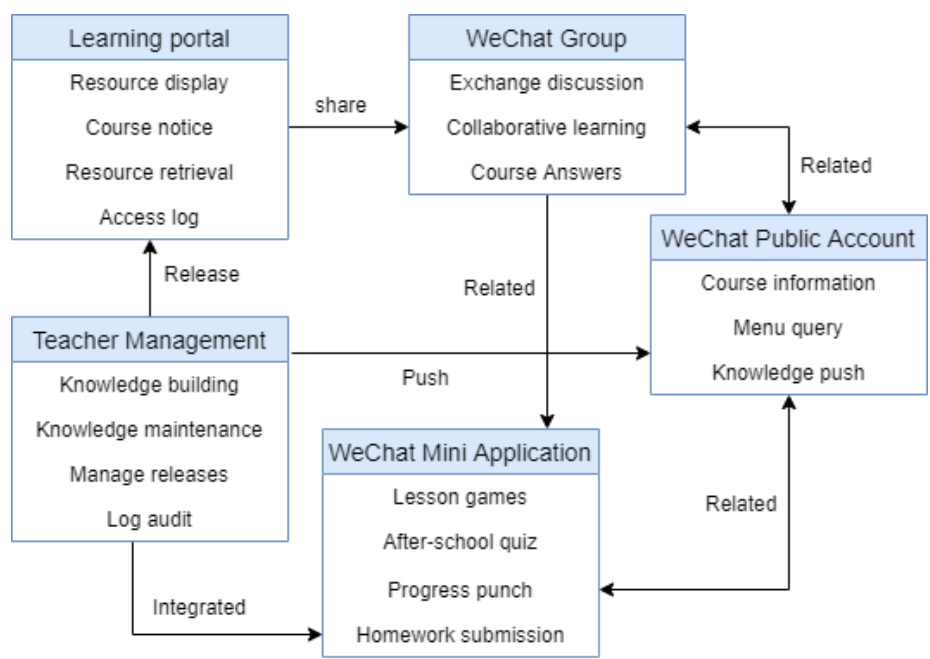

Figure 3 Functional module of E-learning space

\section{ACKNOWLEDGMENT}

This work was financially supported by Humanities and Social Science Youth Foundation of Ministry of Education projects and Guangdong Education Construction Project in China (No. 20YJCZH124) (No. 402-XCQ20021) 


\section{REFERENCES}

[1] Yafeng XU etc. Learning Space: Conceptual Connotation, Research Status and Practice Progress [J] Modern Distance Education Research, 2015(3): 82-94.

[2] Ministry of Education. Education Informatization 2.0 Action Plan [EB/OL].2018-4-18:

http://laws.ict.edu.cn/laws/new/n20180423_49471.shtm 1

[3] Ministry of Education. Guide to the Construction and Application of E-Learning Spaces [EB/OL].2018-416.

http://www.moe.gov.cn/srcsite/A16/s3342/201805/t201 80502_334758.html

[4] Radcliffe etc. Designing Next Generation Places of Learning: Collaboration at the Pedagogy-Space-

Technology Nexus. 2008.

[5] Gail Wilson and Marcus Randall. The implementation and evaluation of a new learning space: a pilot study $[\mathrm{J}]$. Research in Learning

Technology.Vol,20,2012

[6] Jenny NG. Innovating with Pedagogy-Space-

Technology (PST) Framework: The Online Moot Court [J]. Learning Communities.2015(18).52-65

[7] Tencent [EB/OL] WeChat public platform technology development

document:https://mp.weixin.qq.com/wiki?t=resource/re s_main\&id=mp1445241432

[8] Mythp [EB/OL] Development basics of responsive layout: https://www.cnblogs.com/fengyingwang/p/6073795.ht $\mathrm{ml}$ 